\title{
Field-Portable Helium Isotope Detectors for Continuous Monitoring of Volcanic Unrest and Large Earthquakes
}

\author{
GAry M. MCMurtry', JAMES R. DeLuZE², JAMES E. \\ BLESSING \\ Dept. of Oceanography, University of Hawaii, Honolulu, HI \\ 96822 USA, mcmurtry@hawaii.edu \\ Fusion Energy Solutions of Hawaii, 611 University Avenue, \\ Honolulu, HI 96826 USA, jrdeluze@icloud.com \\ ${ }^{3}$ MKS Instruments, Inc., Santa Clara, CA 95054 USA, \\ James_Blessing@mksinst.com
}

Because of the primordial signature of the helium isotope ratio in Earth's mantle, Earth scientists have found it useful to compare and monitor the ${ }^{\mathrm{He}}$ to $\mathrm{He}$ mass abundance ratio in rocks, sediments and volatiles such as free gases and those dissolved in water. In some cases, helium can vary like a strain gauge monitor, responding with deep mobility in the Earth's crust and upper mantle; in other cases, high ratios can indicate the primordial signature of magma batches from a heterogeneous plume and magma reservoir. Several shallow magmatic emplacements and volcanic eruptions, as well as earthquakes, have been documented to show synchronous and precursory changes in the ${ }^{3} \mathrm{He} / \mathrm{He}$ ratio of their volatile emissions, in both gases and fluids. The timescales of these predictive $\mathrm{He} / \mathrm{He}$ ratio anomalies can range from years to within periods of a few days or less. To date, the only means to sample for $\mathrm{He}$ isotopes is using conventional collection techniques with sample return to the laboratory. However, real-time, in situ analysis is necessary to detect any rapid changes in time for effective hazards response and planning. We have made considerable progress in development of an in situ $\mathrm{He}$ isotope analysis system, with initial monitoring results at Mammoth Lakes, CA (Long Valley Caldera) and some intriguing high ratios measured in lower East Rift Zone steaming vents prior to the 2018 eruption and summit collapse of Kilauea Volcano. Our approach uses mainly offthe-shelf component technology combined with state-of-theart electronics and software, as opposed to an expensive "field laboratory" approach, so that multiple units can be deployed and stay within the budgets of volcano and earthquake hazards mitigation agencies globally. 